\title{
LAS TENSIONES SOCIO-ESPACIALES A PARTIR DE LA DECLARACIÓN DE PATRIMONIO DE LA HUMANIDAD Y EL INCREMENTO DEL TURISMO EN LAS PROVINCIAS DE SALTA Y JUJUY DE LA REPÚBLICA ARGENTINA
}

\author{
Catalina Fairstein \\ Universidad de Buenos Aires, CEIL-PIETTE, CONICET
}

http://dx.doi.org/10.5209/rev_NOMA.2013.42345

\begin{abstract}
Resumen.- El presente trabajo analiza las tensiones socio-espaciales a partir de las declaraciones de Patrimonio de la Humanidad (por parte de la UNESCO) y el incremento del turismo en las provincias de Salta y Jujuy. Se toman como casos de estudio la Quebrada de Humahuaca en general y el caso del pueblo de Iruya en particular, por ser considerado paradigmático en las transformaciones que atraviesan. Como contra-caso se consideran las zonas de los Valles Calchaquíes y de la Quebrada del Toro en la provincia de Salta, las cuales cuentan con iniciativas para ser declaradas Patrimonio por la UNESCO. Las tensiones que se mencionan pueden agruparse en tres ejes: el valor y la posesión de la tierra, la disposición y apropiación de los recursos naturales; y las transformaciones de los bienes culturales y los procesos simbólicos. Los dos casos que se mencionan presentan similitudes en tanto las tensiones que los atraviesan pero diferencias en el modo en que se posicionan los actores en las mismas. Para el caso de la Quebrada e Iruya se analiza las pujas a partir de la declaración de Patrimonio y cómo se desarrollan, con mayor o menor éxito, estrategias de reconversión y recuperación. En este caso los actores locales asumieron una posición cuando ya estaban muy avanzadas las disputas y su situación empezaba a visualizarse claramente como desfavorable. Para el caso de las zonas de Salta, que aún no están declaradas Patrimonio, se analizan las prácticas que los actores locales-colectivos realizan fin de analizar, intervenir y capitalizar las ventajas y desventajas de las transformaciones en marcha. Tomando el ejemplo de la Quebrada y bajo el lema "no queremos que pase lo que en Iruya" buscan posicionarse de modo activo en el escenario de tensiones vigentes.
\end{abstract}

Palabras claves.- territorio, tensiones, recursos, patrimonio, actores, turismo

\section{Tensions in the social space since the inscription on the World Heritage List and the increase of tourism: The Salta and Jujuy case - Argentina}

Abstract.- This paper analyzes the social-spacial tensions that followed the inclusion of the Quebrada de Humahuaca on the World Heritage List (UNESCO) and the increase of tourism in Salta and Jujuy provinces. These are case studies on Quebrada de Humahuaca in general and, in particular, the small town of Iruya as a paradigmatic example of the transformations. The counter-cases are the Valles Calchaquíes and Quebrada del Toro regions in Salta, both of them candidates to be part of the World Heritage List (WHL). The tensions can be grouped in three axes: the value of land and its possession; the disposal and property of natural resources and the changes in cultural goods and social symbolic processes. Both cases present common features in the tensions running through, but they are different in the way actors position themselves towards the scenario. In the Quebrada and Iruya cases we analyze the struggle since the inclusion in the WHL and the development of -more or less successful- reconversion and recovery strategies. In this case, local actors defined a position when the tensions were already in an advanced state and their situation was to be clearly perceived as unfavorable. In the case of Saltean regions not yet included in the WHL, we analyze the practices that localcollective actors perform to analyze, intervene and capitalize the advantages and disadvantages of the ongoing transformations. With the example of the Quebrada and with the slogan "We don't want for us what happened to Iruya" they try to position themselves in an active mode in the current scenario of tensions.

Keywords.- territory, tensions, resources, wealth, actors, tourism 


\section{Introducción}

El presente trabajo analiza las tensiones socio-espaciales a partir de las declaraciones de Patrimonio de la Humanidad (por parte de la UNESCO) y el incremento del turismo en las provincias de Salta y Jujuy. Se toman como casos de estudio la Quebrada de Humahuaca en general y el caso del pueblo de Iruya en particular, por ser considerado paradigmático en las transformaciones que atraviesan. Como contra-caso se consideran las zonas de los Valles Calchaquíes y de la Quebrada del Toro en la provincia de Salta, las cuales cuentan con iniciativas para ser declaradas Patrimonio por la UNESCO.

Las tensiones que se mencionan pueden agruparse en tres ejes: el valor y la posesión de la tierra, la disposición y apropiación de los recursos naturales; y las transformaciones de los bienes culturales y los procesos simbólicos. La organización dada al trabajo es mediante apartados que dan cuenta de: 1. Breve (pero necesaria) referencia a qué y cómo se establece el Patrimonio a ser declarado como tal por la UNESCO. 2. El Caso de la Quebrada de Humahuaca, teniendo en cuenta la caracterización geo-física de la zona, las actividades económicas, turísticas, los recursos naturales, el valor y posesión de la tierra, las estrategias de los sectores subalternos en función de la problemática mencionada. 3. El caso específico del pueblo de Iruya. El punto 4 analiza la situación que se atraviesa en la zona de los Valles Calchaquíes. En el apartado 5 el análisis se enfoca en la llamada Quebrada del Toro en la provincia de Salta. Finalmente se enuncian algunas conclusiones preliminares que invitan a reflexionar más que a cerrar el tema.

Los dos casos que se mencionan presentan similitudes en tanto los conflictos que los atraviesan pero se diferencia en el modo en que se posicionan los actores en las mismas. Para el caso de la Quebrada e Iruya se analiza las pujas a partir de la declaración de Patrimonio y cómo se desarrollan, con mayor o menor éxito, estrategias de reconversión y recuperación. En este caso los actores locales asumieron una posición cuando ya estaban muy avanzadas las disputas y su situación empezaba a visualizarse claramente como desfavorable.

Para el caso de las zonas de Salta, que aún no están declaradas Patrimonio, se analizan las prácticas que los actores locales-colectivos realizan fin de 
analizar, intervenir y capitalizar las ventajas y desventajas de las transformaciones en marcha. Tomando el ejemplo de la Quebrada y bajo el lema "no queremos que pase lo que en Iruya" buscan posicionarse de modo activo en el escenario de tensiones vigentes.

En el marco de este trabajo el territorio es comprendido en sentido amplio como una matriz de organización y de interacciones sociales y no como un simple espacio abstracto o un receptáculo de actividades (Alburquerque, 1999). Se constituye como un entramado que permite interpretar en términos culturales y estéticos las cualidades de un lugar (Maderuelo, 2008). El espacio comprende tanto un entorno natural como determinadas prácticas que se entrelazan de modo cotidiano. Por lo tanto no puede ser abordado como una imagen cristalizada y ahistórica, sino como una multiplicidad de factores, elementos y actores, en tensión y movimiento. Esto implica la reflexión sobre este entramado en constante redefinición. El recorte de un tiempo y un espacio tiene un alcance analítico y permite algunas definiciones temporales, sujetas a modificaciones.

\section{Breve referencia a las declaraciones de Patrimonio de la Humanidad}

En el año 1972 la UNESCO establece la Convención para la Protección del Patrimonio Natural y Cultural, entre las consideraciones se destacan aquellas que dan cuenta de la amenaza de destrucción del patrimonio natural y cultural a causa de la evolución de la vida social y económica que agrava las alteraciones (Unesco, 1972). Por lo tanto las declaraciones de patrimonio promueven la protección, el cuidado y la conservación de determinados paisajes y elementos simbólicos, propios de la naturaleza y la cultura. En la misma Convención se establece la responsabilidad de los Estados parte de comprometerse y facilitar recursos y asistencia técnica para favorecer el proceso de protección.

En el año 2003 la UNESCO declara a la zona de la Quebrada de Humahuaca Patrimonio Cultural y Natural en la categoría Paisaje Cultural. Los criterios de la organización se basaron en la importancia como herencia cultural para la humanidad ya que por allí se trazó el Camino del Inca y aún se conservan muchos elementos, actividades, tradiciones, entre otros, de las culturas prehispánicas. El entorno natural también presenta sus especificidades ya que posee una característica geográfica muy particular por estar colindantes (y en zonas de la Quebrada convivientes) espacios áridos y semi-desérticos con formas subtropicales y selváticas.

\section{La Quebrada de Humahuaca - Provincia de Jujuy}

\section{Caracterización geofísica y poblacional}

Desde la Geografía la Quebrada de Humahuaca es definida como una interfase entre la Puna y las sierras sub-andinas y los valles templados, con una altitud que varía entre los 1600 y los 2700 m.s.n.m. Es un estrecho de 155 km. de 
largo y $13 \mathrm{~km}$ de ancho en cuyo valle corre el río Grande de Jujuy. Presenta como características una visibilidad de colores vivos ausentes de vegetación, existencia de desniveles de varios miles de metros, fuertes pendientes y procesos geomorfológicos muy activos (Failde de Calvo; Fernández, 2008).

La región de la Quebrada de Humahuaca está dividida políticamente en tres departamentos: Humahuaca, Tilcara y Tumbaya. Al interior de los mismos se puede identificar parajes y pueblos de mayor o menos densidad poblacional, siendo los más destacados (tanto por la cantidad de población así como también el índice de actividad): Maymará, Uquía, Purmamarca. Se toman para este estudio dos departamentos de la región Puna (Yavi y Susques) y el pueblo de Iruya pertenece a la provincia de Salta pero sólo se accede mediante la localidad de Humahuaca y comparte con esta geografía, historia, economía y cultura. Este conglomerado se construye a partir de identificar problemáticas comunes en las diferentes áreas. Al tiempo que estas localidades se inscriben en el circuito turístico de la Quebrada de Humahuaca.

Los últimos datos poblacionales por región disponibles son los del censo 2001. Se tomarán esto cómo válidos de manera relativa en el curso del análisis. Su relatividad está dada al ponerlos en diálogo con los datos de tipo cualitativos. Según la Dirección Provincial de Estadísticas de la provincia de Jujuy la división poblacional es la siguiente:

\begin{tabular}{|c|l|l|l|}
\hline DEPARTAMENTO & 1980 & 1991 & 2001 \\
\hline Quebrada & & & \\
\hline Humahuaca & 16,817 & 18,183 & 16,765 \\
\hline Tilcara & 7,159 & 8,463 & 10,403 \\
\hline Tumbaya & 4,210 & 4,175 & 4,553 \\
\hline Puna & & & \\
\hline Susques & 2,184 & 2,846 & 3,628 \\
\hline Yavi & 12,861 & 16,533 & 18,160 \\
\hline
\end{tabular}

Si se considera el porcentaje de población rural:

\begin{tabular}{|c|l|l|l|}
\hline DEPARTAMENTO & 1980 & 1991 & 2001 \\
\hline Quebrada & & & \\
\hline Humahuaca & $35,83 \%$ & $32,21 \%$ & $33,55 \%$ \\
\hline Tilcara & $100 \%$ & $64,83 \%$ & $36,57 \%$ \\
\hline Tumbaya & $100 \%$ & $100 \%$ & $100 \%$ \\
\hline Puna & & & \\
\hline Susques & $100 \%$ & $100 \%$ & $100 \%$ \\
\hline Yavi & $36,87 \%$ & $30,50 \%$ & $24,22 \%$ \\
\hline
\end{tabular}

\section{Actividades económicas y productivas}

Las actividades económicas tradicionales de la Quebrada están vinculadas a la especificidad del territorio. Existen variados ambientes con formas productivas 
diferenciadas. Se puede hacer una breve caracterización: En las zonas de pequeña dimensión pero con acceso recursos hídricos se concentra la ganadería (vacunos, pero principalmente la cría de ovejas, cabras, porcinos y llamas). En menor escala se desarrolla fruticultura, horticultura (lechiga, acelga, zanahoria, cebolla, pimiento, perejil, haba, entre otros) y productos andinos como la papa, quínoa, maíces. Finalmente se producen prácticamente para el autoconsumo o para la venta en pequeñas cantidades: plantas aromáticas y medicinales como: orégano, romero, cedrón.

Las explotaciones son familiares en terrenos que suelen tener entre 1 y 3 hectáreas de superficie. Utilizan a los diferentes miembros como mano de obra y sólo en momentos de cosecha o para cierto tipo de cultivos se contrata mano de obra externa a modo de jornaleros. Los ingresos no suelen alcanzar para la subsistencia con lo cual los miembros adultos de la familia buscan trabajos extra prediales. Suelen ser las mujeres y los jóvenes quienes trabajan de modo permanente en la finca, los varones suman ingresos a través de empleos en fincas de mayor tamaño, sector público, construcción, hotelería, etc.

El circuito de comercialización (dado que la producción es en escala pequeña) son las ferias y mercados locales en toda la región del NOA. Muchos productos se destinan al autoconsumo. Tradicionalmente se desarrollaban sistemas de trueque en fiestas locales que coincidían con la celebración de fiestas religiosas (como es el caso de la Manca Fiesta, la Fiesta del Haba o el Culto a la Pachamama). Actualmente, la necesidad de contar con papel dinero implica la modificación de este tipo de comercio.

Esta descripción puede ser analizada desde dos dimensiones que se superponen. Por un lado la cuestión cultural y tradicional y, por otro, la cuestión material. Desde el punto de vista de los estudios culturales más asociados al relativismo esta forma de producción se piensa como emergente de una tradición propia en el modo de trabajar la tierra.

Pero esta forma de dar cuenta de la producción y comercialización corre el riesgo de caer en lo que se denomina la exotización de la cultura indígena (Bidasecca, 2007). La pregunta subyacente es si la posibilidad de acceder a recursos que tecnificaran y tecnologizaran la producción hubiesen permitido una forma diferente de trabajar la tierra. ¿Este modo de producción responde a una especificidad cultural a una situación de subalternidad invisibilizada por la exotización de lo indígena y campesino?

Este trabajo no pretende dar respuesta a esta pregunta, pero sí a dejar de manifiesto que desde los denominados Subaltern Studies de la India es posible interrogarse en este sentido. Cuando Spivak (1985) se pregunta en su texto “¿Puede el hablar subalterno? La respuesta es no. Si pudiera, no estaría en condición de subalterno. Y no estarlo implica el surgimiento de un nuevo bloque histórico en términos de Gramsci (1984), que modifica la estructura de los medios de producción y las significaciones a nivel superestructurales.

No obstante el "no" rotundo de Spivak, se desarrollan en la zona estrategias de resistencia y modificación de las formas en que se suceden los procesos y que 
conducen a empoderar a estos sectores subalternos (o quizás subalternizados, no sólo por los procesos económicos sino también por la forma en que se los pensó desde las ciencias sociales positivistas y relativistas).

\section{Descripción de la explotación turística}

La Quebrada de Humahuaca es uno de los destinos de la Argentina que mayor turistas por año recibe. Este proceso fue paulatino pero creciente de modo sostenido durante todo el siglo XX. Por las características de la quebrada fue un territorio destinado a exploraciones arqueológicas dado que hay una gran cantidad de sitios y espacios de preservación de objetos y santuarios precolombinos. Al mismo tiempo las formas rocosas y montañosas, ausentes de vegetación, de los Andes menores ofrecen posibilidades de exploración para la geología y la geografía. La vigencia de los pueblos originarios en la zona presentó un atractivo para los estudios antropológicos.

Hacia mediados de la década del 40 la provincia de Salta ya concentraba turismo local y ofrecía a modo de excursión un día de turismo en la Quebrada de Humahuaca. La primera corriente de expansión hotelera de la zona se produce hacia 1960 y se consolida en la década posterior, donde se constituye como destino turístico propio en el que confluyen las excursiones por el día con los turistas que se hospedan en la Quebrada por una o dos noches, generalmente en el período estival del cono Sur (Troncoso, 2008).

A partir de la década del 90 aumenta exponencialmente el número de turistas que permanecen en la zona, crece la oferta hotelera y gastronómica y se incrementa la infraestructura vial y receptiva al tiempo que se abren nuevos puntos y pueblos como receptores de turistas.

La declaración de Patrimonio en el año 2003 produce un salto en el crecimiento sostenido que venía experimentando el sector: para 1994 el 6\% de los turistas que llegaban a Jujuy recorría la Quebrada de Humahuaca, en el año 2005 lo hacen el 30\%. La permanencia de los turistas en la zona era de 1 día en 1998 y de 3 días en el 2005. La ocupación hotelera en la Quebrada en 1994 era del 13\%, en el 2006 es del 53\% promedio anual, con una ocupación del 100\% en el mes de Enero en el pueblo de Tilcara (Troncoso, 2008).

Los datos indican que en el año 2003 la zona de la Quebrada tenía una oferta de 54 alojamientos para cubrir 1072 plazas. En el año 2008 sólo el departamento de Tilcara cuenta con 1170 plazas de hospedaje. Estos datos permiten dar cuenta de un crecimiento de la actividad no siempre acompañado de políticas de promoción social y conservación del paisaje y del patrimonio así como de los recursos naturales y ambientales de la zona.

En la Quebrada la actividad turística se da de modo sostenido durante todo el año, en los meses de septiembre y octubre la procedencia es principalmente del exterior, en los meses de enero, febrero y marzo es local. Las características de los turistas son muy heterogéneas así como la oferta. Por un lado hay hoteles de categoría que reciben turistas con alto poder adquisitivo, 
esto convive con una gran cantidad de turismo joven que realizan viajes de bajo costo como mochileros y suelen hospedarse en hostel o en campings.

Este aumento de la actividad turística se debe a que la política cambiaria es favorable para el turismo proveniente del exterior. Pero al mismo tiempo esta dificulta el turismo hacia el exterior a nivel nacional. Por lo tanto se conjuga la gran afluencia de turismo extranjero como de turismo interno.

\section{$\underline{\text { Recursos naturales y simbólicos }}$}

Las implicaciones en el territorio se pueden observar en diferentes actividades. Una de las formas más explicitas y visibles es la construcción de hoteles de lujo con piletas de natación en zonas semi desérticas donde el agua escasea. Esto no sólo da cuenta de de la falta de criterio con la que se llevó adelante la planificación. Sino que también pone de manifiesto quienes son los beneficiados y quienes los perjudicados en el acceso a los recursos naturales en la Quebrada.

Dado que la mayoría de los pobladores locales son trabajadores rurales o bien tienen fincas apara el autoconsumo a la escasez natural de agua (por ser una zona semidesértica) se suma a que la poca que hay se destina a los hoteles, deja a estos sectores de la población con recursos muy limitados para la reproducción de su vida cotidiana.

Si se vuelve sobre los datos poblacionales mencionados al inicio se puede prestar atención al comportamiento de la línea que indica la población rural. Para esto se toman dos pueblos. Tilcara y Yavi.

Transformaciones en el volumen de población rural

\section{Porcentaje de Población Rural}

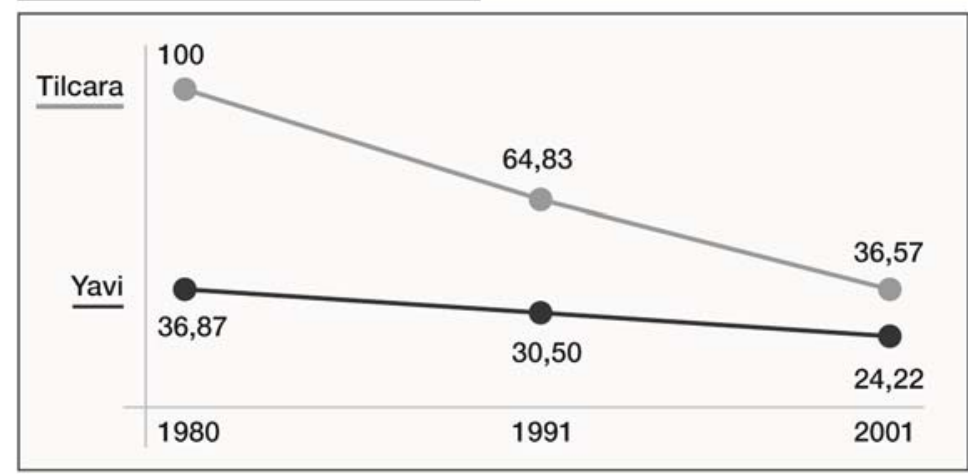

En el caso de Tilcara el paso del 100\% a 36,57\% da cuenta de una proyección claramente desfavorable para los sectores rurales. Si esto se lo pone en diálogo con datos de orden cualitativo, el número adquiere aún más sentido. En el mes de abril de 2011 estando en la zona se sucede un diálogo informal con un trabajador de transporte. Ante mi comentario de la proximidad de la lluvia, me responde que eso no los favorece porque Tilcara "es un pueblo turístico"1.

\footnotetext{
${ }^{1}$ Conversación informal con remisero de la localidad de Tilcara en Tilcara, provincia de Jujuy, abril del año 2011, registrada en notas de campo propias.
} 
Esto permite repensar las implicancias del turismo cuando se tiene en cuenta que en 1980 Tilcara era una población considerada el 100\% rural y 31 años después se piensan a sí mismos como una población turística. Pero al mismo tiempo se puede suponer que más allá de los datos cuantitativos que confirman la reducción de la población rural, el hacer sentido común la idea de lugar turístico permite la apropiación de recursos naturales por parte de los dueños de los grandes emprendimientos.

Como se analizará en un apartado posterior, no es la población local la que lleva a delante la actividad turística. Si bien no hay datos que reflejen la instalación real de emprendimientos, es visible al observador y mediante entrevistas, que los mismos no son propiedad de los tilcareños. Sino más bien que estos terminan ocupados como mano de obra en construcción, trabajo doméstico y servicios asociados al turismo.

Al mismo tiempo, si bien la población rural disminuyó en volumen y en capacidad productiva hay dos cuestiones que no deben ser dejadas de lado. Aún existe población rural en Tilcara (y en toda la quebrada) que intenta no quedar subordinada al proceso del turismo. $Y$ por otro lado, muchas familias que no se consideran rurales a fines estadísticos, sí poseen alguna forma de cultivo para autoconsumo.

De todos modos la concentración de recursos afecta a la población independientemente del carácter de la misma. La falta de agua (sea para el riego o para el consumo) no es un problema para los grandes hoteles y emprendimientos gastronómicos, pero sí para las familias que tienen que desarrollar su vida cotidiana. Misma situación sucede con la electricidad, el gas y el acceso a bienes de consumo.

En concordancia con el acceso a recursos naturales se puede establecer un paralelismo con los recursos de carácter simbólico y cultural. Paradójicamente la declaración de Patrimonio tiene que ver, como se mencionaba anteriormente, con un determinado acerbo cultural vigente y propio de la Quebrada. Se toma a modo ilustrativo lo que sucede con la artesanía local, pero esto se extiende a los relatos, las tradiciones las memorias, los sitios arqueológicos entre otros elementos que construyen el patrimonio.

Los turistas llegan ávidos de consumir las artesanías locales, pero la producción de la zona por su carácter artesanal no alcanzaba a satisfacer la demanda. Las artesanías solían ser una actividad complementaria a la actividad principal, al encontrar allí una veta de mejorar la calidad de vida, las poblaciones locales se abocaron a la venta de artesanías masivas industriales, no sólo más baratas sino de producción más económica lo que les permitía aumentar las ventas con menos inversión. De este modo se dejaron de lado las producciones originarias artesanales por productos de imitación fabricados en serie. 
En una conversación con una vendedora de la plaza de Tilcara en abril de 2011 se mencionaba que "antes yo hacía, toda mi familia hacía (en relación al tejido). Pero ahora compramos en Bolivia y traemos. Hacer es muy caro y no rinde" 2

Las transformaciones que emergen en las poblaciones locales implica el tránsito de un proceso de invisibilidad histórica a uno de hipervisibilización: la exotización de la cultura indígena, la mercantilización del ser, la resistencia de los sujetos a ser desplazados de sus tierras/territorios, a volverse servidumbre en su propia tierra (Bidaseca, 2007).

\section{El valor de la tierra}

Uno de los elementos centrales fue el desplazamiento poblacional y el valor de la tierra. Ante la promoción al turismo aparecieron en la zona inversores extranjeros o de la Ciudad de Buenos Aires con la intención de construir un hotel o emprendimiento gastronómico.

La mayoría de las familias ocupaban los terrenos por años pero no tenían el título de propiedad de la tierra. Esto provocó una serie de expropiaciones de pobladores originarias hacia la periferia de los pueblos. Quienes sí tenían título de propiedad pero no vivían en forma permanente en la zona debieron instalarse de modo permanente a fin evitar las tomas de tierras por parte de empresarios que en convivencia con sistemas gubernamentales corruptos ocupaban las propiedades. Aquellas familias que alquilaban tuvieron que trasladarse a la periferia por el valor de los alquileres.

Se estima que sólo el 30 por ciento de la superficie de la Quebrada de Humahuaca está mensurada. Un mismo terreno puede llegar a tener tres o cuatro pretendientes, algunos con supuestos papeles en regla. Los registros oficiales incluyen propietarios que murieron en 1916. Y donaciones que, en lugar de estar respaldadas por escrituras públicas, sólo cuentan con el aval de jueces de paz, más bien expertos en sellar matrimonios. Hasta los cementerios quedan atrapados a veces en los alambrados de apuro (Calvo, 2007).

El ejemplo más evidente de esto es el caso del departamento de Tilcara donde el valor del metro cuadrado de tierra llego a ser más caro que en el barrio de Recoleta (el más elegante y caro de la Ciudad de Buenos Aires). En este departamento se ofrece, para el mes de Agosto de 2010, una hectárea en la localidad Huacalera a 225.000 dólares. El ingreso promedio de una persona en la quebrada es de \$AR. 2000 (USD 506) por familia por mes. En una provincia donde la tasa de desocupación es del $20 \%$.

Paralelamente no existe un código de edificación que regule las nuevas construcciones tanto por los materiales que se utilizan (lo típico del lugar es el adobe y la paja) está siendo reemplazado por el ladrillo y el cemento así como por los edificios de dos plantas e incluso tres. "A esto se suma que en los últimos años proliferaron las antenas telefónicas, las redes de media tensión,

\footnotetext{
${ }^{2}$ Conversación informal con vendedora de artesanías de la localidad de Tilcara en Tilcara, provincia de Jujuy, abril del año 2011, registrada en notas de campo propias.
} 
las plantas de reducción de gas y otros equipamientos de gran visibilidad" (Diario La Nación, 2007).

Parte de este proceso se debe a que el gobierno nacional delegó la planificación estratégica al Gobierno Provincial de Jujuy que su vez la delegó a los municipios. Estos por falta de recursos, experiencia y apoyo de las instituciones del Estado no lograron cumplimentar el plan para el año 2004, un año después de la declaración de patrimonio, pero sí se avanzó en construcciones, promoción turística y desalojo de las familias locales que no podían demostrar la posesión de la tierra. Esta situación se genera por años de atrasos en las regulaciones dominiales sumado a las convivencias de terratenientes locales, inversionistas y funcionarios corruptos de los diferentes niveles del Estado.

Caminar por los pueblos de la Quebrada (en especial en Tilcara y en Humahuaca) implica ver que muchas propiedades muestra la siguiente fachada:

Fachada de casa en el pueblo de Tilcara

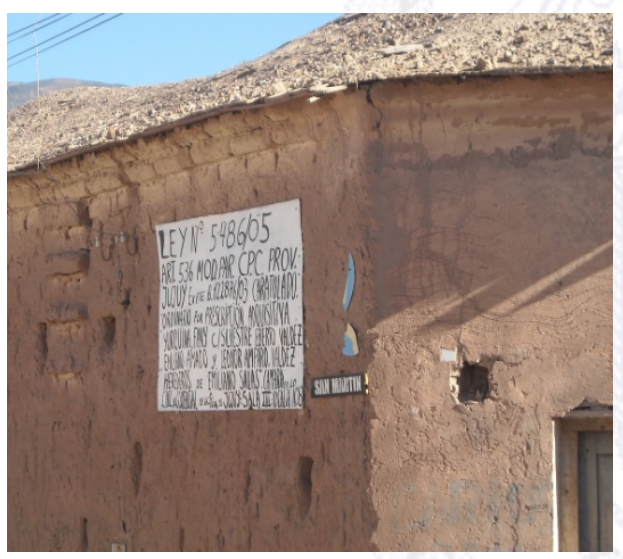

El cartel da cuenta de que la propiedad se encuentra en litigio judicial para determinar la situación dominial. Esto implica que el conflicto adquiere el carácter privado de una familia contra un supuesto propietario. Con los costos que el proceso implica y en una situación de evidente desventaja. Quienes no lograron llegar a esta instancia fueron desplazados hacia barrios realizados ad hoc por el Fondo Nacional de Vivienda (llamados Barrios Fonavi). Este permite suponer una convivencia de estos supuestos propietarios con el Estado que, por un lado garantiza el acceso a tierras que no les pertenece y por otro otorga viviendas sociales a quienes fueron desplazados.

\section{El caso del pueblo de Iruya}

Si bien este apartado reviste un carácter puramente descriptivo Iruya se toma como ejemplo por la representatividad en el alto grado de impacto (negativo) que tuvo el aumento turismo (asociado a la declaración de Patrimonio El departamento de Iruya es una localidad de la provincia de Salta pero, por su 
ubicación geográfica, sólo se accede desde la Quebrada de Humahuaca (vía terrestre por el pueble de Humahuaca) en la provincia de Jujuy.

Iruya es una localidad ubicada a 2780 m.s.n.m. El pueblo propiamente dicho concentra 1000 habitantes, pero tiene una población total de 6000 habitantes distribuidos en 3500 km2, a razón de 1,8 habitantes por km2. La población rural es de 1877 habitantes, pero la mayoría de las familias poseen pequeñas quintas para autoconsumo, se considera que 2589 habitantes viven en asentamientos tipo rancho ${ }^{3}$. Un gran porcentaje de la población son indígenas y pueblos originarios. Según el censo del año 2001 el 49.7\% de la población registraba NBI, la tasa de analfabetismo es de 5,1\% y cuenta con 27 escuelas EGB y 3 Polimodal todas ellas dependientes del Estado.

El Anuario Estadístico de la Provincia de Salta, indica que en el año 2008 Iruya contaba con sólo dos hospedajes (con características de hoteles) con una capacidad de 48 plazas en total. Pero al analizar la oferta detallada tanto en terreno como la que se publica por medios electrónicos se registran 8 tipos de alojamiento extra-hoteleros (casas de familias, hosterías no registradas, etc.). Y una gran cantidad de zonas donde se asientan carpas que no están reguladas ni controladas de forma alguna.

Esto se debe a la evolución en el número de turistas que reciben. En el año 1997 partían dos micros por semana desde la localidad de Humahuaca, en el 2010 sale uno por día. En época de carnaval, durante el mes de Febrero, salen 5 micros por día, y a la única empresa que hacía el traslado (Empresa Mendoza) se sumaron dos más, una desde Humahuaca y otra desde Tilcara. En el período estival Iruya recibe 400 turistas al día.

Las transformaciones son similares a las sucedidas en el resto de la Quebrada de Humahuaca, pero quizás de mayor profundidad. Por ser Iruya una localidad muy pequeña y casi aislada la llegada de un número de turistas inusitados trajo aparejado la escasez de recursos naturales, la incapacidad de contener las demandas de alimentos y alojamientos y el impacto en el entorno natural.

Quizás las mayores transformaciones se pueden detectar a nivel socio-cultural, la mayor parte de la población de Iruya es rural y de la etnia kolla. Muchos de los turistas que llegan son mochileros o neo-hippies quienes trasladan sus hábitos a una cultura diferente. Esto impacta en por lo menos dos aspectos, por un lado se crean nuevas necesidades que la comunidad no tenía (vinculadas básicamente a elementos tecnológicos). Los niños admiran los reproductores de música, computadoras portátiles, internet, y diversos elementos electrónicos que comienzan a ser demandados generando nuevas formas de discriminación. Por otra parte se sucede un intercambio de culturas que no se enmarca en el respeto sino en el avasallamiento, los turistas bajo esta caracterización transitan por el pueblo en traje de baño o con el torso desnudo, consumen marihuana en público y se asientan en cualquier lugar disponible, generando todo tipo de basura.

\footnotetext{
${ }^{3}$ Construcción típica de áreas rurales en el NOA, tiene generalmente paredes de adobe, piso de tierra y techo de chapa o paja.
} 
Para las poblaciones rurales indígenas esto implica una modificación de su vida cotidiana para la cual no se encontraban debidamente preparados, al tiempo que no se desarrollaron de modo conjunto con el Estado estrategias de prevención de este tipo de situaciones. Muchas familias abandonan sus actividades tradicionales porque encuentran en la atención del turismo una mayor y mejor fuente de ingresos, pero esto es temporal, ya que en períodos de baja receptividad los ingresos disminuyen pero como el dinero se destina a otros canales de circulación y comercialización, no se re-invierte en actividades productivas, generando pobreza en el mediano plazo. Al tiempo que se generan una exotización de la cultura local y de la vida cotidiana como estrategia adaptativa al mercado de consumo para el turismo.

En la actualidad se presentaron proyectos por parte de las organizaciones rurales, kollas, aymaras y de otros pueblos originarios locales para generar emprendimientos de turismo comunitario que intenten revertir la situación aplicando una política de recepción, códigos de convivencia y prácticas de turismo responsable. Estas iniciativas son incipientes y se proponen revertir esta situación. Pero estas propuestas luchan y conviven con lo ya asentado que se propone sostenerse y expandirse a pesar de los efectos adversos que genera.

\section{Los Valles Calchaquíes en la provincia de Salta}

Para el estudio del contra-caso se toman dos zonas de la provincia, los Valles Calchaquíes y la Quebrada del Toro. Ambas zonas presentan las siguientes características comunes: El Estado local pretende que sean declaradas Patrimonio de la Humanidad; desde hace años reciben un aumento en la cantidad de turistas de modo sostenido; las poblaciones son (en un gran número) rurales y originarias; desarrollan estrategias tempranas para morigerar y canalizar el impacto del turismo; construyen a partir de lo sucedido en Iruya y usan casi como consigna "no queremos que pase lo que pasó en Iruya"4.

\section{Características geográficas y poblacionales}

La localidad de Cafayate se encuentra en el área de los Valles Calchaquíes, que llegan hasta la provincia de Tucumán y se considera la frontera Sur del Imperio Inca. Se ubica a $183 \mathrm{~km}$. al sur de la provincia de Salta y está a 1660 m.s.n.m. Es una fracción de los que se denomina Andes Meridionales.

Tiene una población total de 11.785 habitantes de las cuales 1071 se considera rural. Una de las localidades cercanas más importantes es San Carlos con una población 7208 habitantes, según la Dirección Provincial de Estadísticas, está considerada rural en su totalidad. Siguiendo por la misma ruta se encuentran algunos parajes como: Angastaco con una población de 2.518 habitantes y Animaná de 1.454, en estos dos últimos casos el total de la población está considerada de carácter rural (Angélico; Fairstein, 2008).

\footnotetext{
${ }^{4}$ Esto es repetido en varias oportunidades en las reuniones de los pobladores de la zona. Registro de notas de campo propio para los años 2007, 2008 y 2009.
} 


\section{Actividades económicas}

La explotación rural y agropecuaria (también mencionada como tradicional) en la zona se la puede identificar en dos grandes formas diferenciadas tanto en volumen, proceso productivo y tecnología. Hay un expansivo desarrollo del cultivo de la vid, básicamente de uva para vino Torrontés, vinos de alta gama y vinos de altura.

Esta explotación está a cargo de grandes bodegas, la mayoría de ellas de capital transnacional. Son los propietarios de los viñedos, la tierra y la bodega en sí. Por lo tanto concentran todo el proceso productivo y de comercialización. Algunos de estos establecimientos también poseen hoteles gerenciados por grupos económicos como es el caso de la bodega El Esteco.

Otro de los cultivos característicos de la zona es el pimiento rojo para la producción de pimentón. Pero aquí la dinámica productiva es distinta al caso de las bodegas, ya que hay un gran número de pequeños productores de pimiento rojo que venden la materia prima a grandes compañías que lo procesan y comercializan el producto terminado. Las dos grandes empresas compradoras son Alicante y La Virgina.

Por lo tanto este sector representa una economía fuertemente concentrada que acapara por un lado el proceso productivo y el circuito de comercialización, y por otro lado define los precios en el mercado y determina de este modo el valor de compra a los pequeños productores. La escala del pequeño productor local es de entre 1 y 3 hectáreas, la mayoría en la modalidad de arrendatario o mediero.

Uno de los mayores problemas es del agua ya que el consorcio hídrico local asigna más horas de riego a los grandes bodegueros que a los pequeños productores. Establecen las horas de riego según la cantidad de hectáreas que se poseen. Este es uno de los principales motivos por los cuales no es posible una dedicación exclusiva de los pequeños productores a la propia finca.

\section{$\underline{\text { Actividad turística }}$}

Los datos estadísticos indican que la provincia de Salta recibía 461.429 turistas en el año 1997, para el año 2008 el número de turistas recibidos fue 1.256.706. En Cafayate se asienta lo que se denominó turísticamente la ruta del vino, que es un recorrido por una cantidad de bodegas desde grandes empresas hasta emprendimientos familiares que ofrecen visita, recorrido de los viñedos y las formas de producción, degustaciones y en algunos casos hospedaje de lujo.

Este crecimiento generó un gran impacto socio económico en un doble sentido. Por un lado aumentaron notablemente los ingresos totales de la provincia de Salta no sólo para los directamente afectados sino también abriendo puestos de trabajo en el área de la construcción y los servicios así como en la expansión de expresiones culturales y artísticas propias de la zona. 
Pero por otro lado la mayoría de los nuevos emprendimientos turísticos son llevados adelante por capitales del extranjero, de la Ciudad de Buenos Aires o familias locales dueños de grandes extensiones de tierra. Al mismo tiempo la promoción turística no estuvo acompañada de las inversiones necesarias, ni del cuidado y protección del entorno natural, las poblaciones preexistentes en la zona, el paisaje, el ambiente, las economías regionales y el territorio. Más bien por el contrario.

Al ser el pueblo de Cafayate una zona turística de más larga data, los parajes aledaños que comenzaron a notar la afluencia en los últimos veinte años comenzaron tempranamente a desarrollar estrategias organizativas a fin de canalizar y orientar el turismo hacia el viajero responsable, el respeto por la cultura local y el sostenimiento de las actividades productivas rurales en convivencia con el turismo. Es en este contexto que surge la Red de Turismo Campesino (en adelante RTC) como ONG que permite organizar, discutir y disputar el ordenamiento territorial y simbólico a modo de planteo contrahegemónico al del turismo tradicional.

\section{Estrategias en desarrollo ante las transformaciones}

La Red de Turismo Campesino (RTC) es un emprendimiento que llevan adelante familias de la zona a fin de promover actividades en el marco de lo que se denomina turismo comunitario. La RTC se genera para brindar el servicio de alojamiento pero también intenta promover un circuito productivo y de comercialización propio. Mediante la venta de artesanía local (cerámica, madera, tejidos, plata, dulces, etc.), las comidas típicas, y los guías locales, se ofrece un servicio integral donde todas las demandas turísticas sean cubiertas por la RTC. Tiene por objetivo que el turista comparta las actividades propias de los integrantes, pero se promueve a que el turismo no reemplace las otras actividades que las familias realizan.

El servicio que ofrece la RTC es de hospedaje en las casas de las familias y la comida tradicional de la zona. El objetivo es el intercambio cultural y el crecimiento tanto de las familias como de los visitantes. Para lograr esto son muy rigurosos en la elección de turistas que reciben así como en la permanencia de los viajeros. Poseen un Código de Conducta del Turista y un Reglamento Operativo Interno donde se plasman sus normas de trabajo.

El turista paga un costo según el paquete elegido. El $80 \%$ de ese ingreso queda en la familia que lo ha alojado, y el $20 \%$ se destina al fondo común de la RTC. Al mismo tiempo pagan un pequeño monto por costo operativo de la organización. Cada familia realiza, en la medida de sus posibilidades, un aporte mínimo en dinero por año para lograr cubrir el costo operativo por año.

La RTC tiene para las familias un sentido pluridimensional. Una de las dimensiones es lo que afecta a la calidad de vida. Al mejorar sus casas para recibir a los turistas, las familias mejoran su calidad de vida, ya que se apunta a la erradicación de los baños letrina, la humedad y goteras en los ambientes, el mejoramiento de la infraestructura habitacional en general, esto repercute positivamente en las familias, estén recibiendo o no turistas en ese momento. 
De este modo el objetivo final es intervenir positivamente en las transformaciones que se producen a partir de cambios en las actividades sociales de la población. Se busca que se mantengan las tradiciones, prácticas y actividades de la cultura local. Se le propone al visitante ser parte por un período de esas actividades y se intenta mejorar la infraestructura, cuidar el ambiente y promover la permanencia de la población en la zona a partir del fortalecimiento de las actividades rurales y agrarias.

Se pude establecer un paralelo entre la situación en la Quebrada de Humahuaca y en los Valles Calchaquíes. Así como el pueblo de Humahuaca tuvo un crecimiento sostenido del turismo, que por flujos intensos creció súbitamente en los últimos 10 años afectando de un modo no previsto a la localidad de Iruya, una escenario similar se produce en los Valles Calchaquíes. Cafayate mantuvo un crecimiento sostenido del turismo en los últimos años, los flujos se intensificaron y comenzaron a diversificarse hacia San Carlos y parajes aún más pequeños, que teniendo como antecedente lo sucedido en Iruya, se organizan promueven estrategias diferentes para evitar situaciones análogas.

\section{Las tensiones territoriales}

Lo que lleva adelante la RTC, más allá del emprendimiento en sí, es una resignificación del territorio tanto en sus inscripciones materiales como simbólicas, e incluso discursivas. La relación con el territorio se podría caracterizar como dialéctica, en términos de "experiencia" (Robins y Aksoy, 2005) dado que permite abordar las discontinuidades, los cambios y las divagaciones más que la continuidad de una identidad reificada. Por un lado determina las prácticas de los actores, en tanto actividades rurales y culturales. Pero al mismo tiempo marcan el territorio a partir de la práctica.

Para las grandes bodegas y emprendimientos turísticos el territorio es un espacio a conquistar, explotar y fuente privilegiada para la generación de ganancias. Para los miembros de la RTC el territorio es un espacio a respetar, cargado de de sentidos y significaciones. Los miembros de la RTC piensan el territorio como un lugar cuasi sagrado, donde convive la producción y el cultivo con el mito y el relato. Perciben como invasiva y poco respetuosa la utilización de mera explotación que las empresas (en tanto otros) hacen del territorio.

Al dejar establecido que se mejora tanto la infraestructura comunitaria como la arquitectura de las casas, se enfatiza la necesidad de establecer ventajas comparativas como estrategia para competir en el mercado turístico local posicionándose con una oferta diferenciada pero estéticamente atractiva.

Se relaciona con lo que propone Ávila Moreno: "la posibilidad de los sujetos sociales de expresarse cada vez más en y desde diversos registros culturales; de combinar en sus prácticas culturales cotidianas elementos procedentes de contextos culturales diversos" 5 .

\footnotetext{
5 Ávila Molero, J. (2006) Andes trans/nacionales. Globalización, (in)migración y rituales
} religiosos. P. 12. Colección Monografías, № 31. Caracas: Programa Cultura, Comunicación y 


\section{La Quebrada del Toro}

\section{Características geográficas y poblacionales}

La Quebrada del Toro pertenece al departamento de Campo Quijano y posee una población de 12.500 habitantes según el Censo del año 2001. Esta Quebrada es el camino que comunica el Valle con la Puna. Tiene una altura de 1580 y 3500 m.s.n.m. desde la zona baja hasta las zonas altas, esto implica características de vegetación y producción diferenciadas en cada tramo.

Tiene una longitud de $70 \mathrm{~km}$. y es atravesada en su mayoría por la ruta nacional $\mathrm{N}^{\circ} 51$, conocida como el paso internacional a Chile y es el tránsito obligado hacia la localidad de San Antonio de los Cobres (de características puneñas) desde la cual sale el Tren a las Nubes que atraviesa la Quebrada en varios tramos. Está compuesta por nueve parajes y depende del municipio de Campo Quijano, a $30 \mathrm{~km}$. de la capital de la provincia de Salta.

\section{Actividades económicas}

La población local es de origen Tastil (cultura preincaica) y continúan muchas de sus prácticas ancestrales de modos tradicionales. La agricultura de la zona se concentra en el cultivo de habas, arvejas, papas andinas, maíz y tubérculos e la parte en la parte alta. En las zonas bajas se concentran los frutales (manzana, durazno, pera, manzana, nogal). Con respecto a la ganadería en la zona alta se cría llamas, ovejas, y cabras mientras que en la baja es más significativa la cría de ganado vacuno. Hay un gran desarrollo de la elaboración de quesos y artesanías en lana, madera de cardón.

También es importante el desarrollo de una agricultura de subsistencia, que se da sólo en parcelas de cultivos ubicadas en las quebradas que cuentan con ríos y arroyos. La zona posee $39,4 \%$ de hogares con NBI lo que generó tal impacto que las migraciones hacia la ciudad de Salta y el departamento de Campo Quijano requirieron de la intervención del Estado que mediante políticas de promoción de las actividades rurales y mejoras en los establecimientos educativos y de salud, promueven la permanencia de la población en peligro de migrar.

\section{Actividades turísticas}

Si bien la zona es turística, el turismo que se acerca es por el día y suele llegar directo a al pueblo de Santa Rosa del Tastil, en la cual abundan los sitios

Transformaciones Sociales, CIPOST, FaCES, Universidad Central de Venezuela. 49 págs. Disponible en (acceso 14/5/2011): http://www.globalcult.org.ve/monografias.htm 
arqueológicos de fácil acceso, desde allí se trasladan hacia San Antonio de los Cobres desde donde se accede al Tren a las Nubes.

El caso del Tren a las Nubes se pretende profundizar futuras investigaciones. Se lo considera el más atractivo del mundo porque asciende a 4200 m.s.n.m. en un recorrido de $217 \mathrm{~km}$. Si bien nace en la década del 70 como un emprendimiento turístico, fue utilizado por las poblaciones locales para el traslado formó una fuente privilegiada de empleo para los habitantes de la zona. En la década del 90 fue privatizado y luego de períodos de funcionamiento intermitente hasta su cierre definitivo. Se puso en funcionamiento nuevamente en el año 2008 por una empresa privada de capitales argentinos. La nueva gestión implicó una notable reducción de la mano de obra ocupada en el tren así como aumentó exponencialmente la cantidad de turistas que lo usan a un valor de USD 140 dólares el pasaje, y USD 60 para los residentes en Salta.

El renovado funcionamiento del Tren a las Nubes, sumado al sostenido aumento de la cantidad de los turistas que recibe la provincia de Salta y el expediente para la declaración de Patrimonio de la Humanidad promovido por el Estado ante la UNESCO, incentivaron a la población local a organizarse en función de contener y canalizar las incidencias a partir del conocimiento de experiencias sucedidas en las zonas anteriormente mencionadas.

La Quebrada del Toro cuenta con un recurso privilegiado que es un numeroso conjunto de organizaciones sociales locales entre las que se destaca: Comisión de Turismo y Artesanías de la comunidad Santa Rosa de Tastil, Consejo Indígena del Pueblo Tastil de la Quebrada del Toro, Comunidad Indígena de Gobernador Solá y Alisal, Comunidad Indígena San Bernardo de las Zorras. Estas comunidades retomaron la experiencia de la RTC y comenzaron a informarse y adquirir conocimientos que promuevan la protección del territorio.

Desde el año 2005 se llevan adelante reuniones que tienen como objetivos: generar solidaridad y trabajo asociativo, información y ejercicio de derechos sociales, económicos y culturales, regularización de la posesión de la tierra, reconocimiento formal de las organizaciones sociales, revaloración de la historia, recuperación de la memoria y de la identidad del pueblo de Tastil, mejoramiento de la producción y comercialización tradicional y la construcción conjunta de un espacio de contención social.

\section{Conclusiones}

La declaración de Patrimonio de la Humanidad y el crecimiento de la actividad turística, podrían ser considerados a priori como dos instancias que debieran favorecer a los lugares en los cuales se aplica. La UNESCO busca la protección y conservación del patrimonio natural y cultural de zonas en riesgo, fomentando su cuidado y preservación. Por otra parte, la actividad turística, genera un impulso ascendente de la actividad económica que repercute en diferentes instancias de la vida social. 
Los casos mencionados permiten suponer que lo que conduce a situaciones no esperadas, sea probablemente, la falta de instancias específicas de regulación y promoción que acompañen ese proceso. Tal como se mencionó en el caso de la Declaración de Patrimonio de la Humanidad de la Quebrada de Humahuaca.

Sería reduccionista suponer que los problemas sólo están vinculados al incremento del turismo y la declaración de Patrimonio. La situación desfavorable en relación al mercado de las familias rurales y los pequeños productores es de mayor profundidad. En este escenario conviven la ausencia de políticas por parte del Estado que promuevan el acceso a recursos materiales y naturales, la regulación respecto del valor y posesión de la tierra, el reconocimiento de las poblaciones locales, entre otros.

Las tensiones en torno al territorio que generan el aumento del turismo y la declaración de Patrimonio permiten la emergencia y visibilidad de problemas preexistentes que se profundizan por el impacto del turismo. La paradoja es que aquello que se declara patrimonio para ser conservado es cada vez más debilitado por la misma declaración. A esto se suma situaciones aún no muy exploradas, y que circulan como rumor en las poblaciones locales, como el intento de instalar minas a cielo abierto o la posibilidad de cultivo de soja en terrenos que hasta hoy se utilizan para el pastoreo.

La situación de subalternidad en la que se encuentran las familias rurales y los pequeños productores no comienza con el turismo ni con la declaración de patrimonio. Como se mencionaba al comienzo se podría pensar que el proceso hipervisibilización y exotización de las comunidades locales, garantiza la continuidad de la subalternidad de estas poblaciones. El pasaje de un estado a otro conlleva el transformar la desigualdad en pintoresca.

No puede negarse que la imagen del pimiento rojo secándose al sol a lo largo del valle con los contrastes de colores entre el rojo intenso, el marrón y el verde es una de las postales más bellas de la región. Pero sí es dable interrogarse sobre ese modo de secar el pimiento. La exposición a plagas, daño de la cosecha y disminución del valor del producto no es una cuestión cultural, sino material. Ese sistema no está desarrollado para que el turista pueda tener una vista agradable o porque tradicionalmente se hace así, sino porque los pequeños productores no tienen los recursos económicos suficientes para acceder a métodos de secados industrializados. Por lo tanto si llueve se arruina no sólo una postal, sino la posibilidad de subsistencia de gran parte de las familias del valle.

\section{Referencias bibliográficas}

(2008) ANGÉLICO, Héctor y FAIRSTEIN, Catalina "Las prácticas asociativas de familias rurales. La experiencia de la Red de Turismo Campesino de la provincia de Salta". En: Facultad de Economía de la Universidad de San Pablo, $\checkmark$ Encontro de Pesquisadores Latinoamericanos de Cooperativismo. 
(2006) ÁVILA MOLERO, Javier "Andes trans/nacionales. Globalización, (in)migración y rituales religiosos". P. 12. Colección Monografías, No 31.

Caracas: Programa Cultura, Comunicación y Transformaciones Sociales, CIPOST, FaCES, Universidad Central de Venezuela. 49 págs. Disponible en (acceso 14/5/2011): http://www.globalcult.org.ve/monografias.htm

(2007) Bidaseca, Karina, Comunidad y derecho a la tierra: órdenes jurídicos y procesos culturales silenciados. En e-l@tina. Revista electrónica de estudios latinoamericanos. [On line]. Vol. 5, No 19, abril-junio de 2007, http://www.iigg.fsoc.uba.ar/hemeroteca/elatina/elatina19.pdf

(1984) GRAMSCI, Antonio. Notas sobre Maquiavelo, sobre la Política y el Estado Moderno. Nueva Visión, Buenos Aires.

(2007) Ramos Carmen María. (diciembre, 9). "Enamorados de la Quebrada". Diario La Nación. Argentina.

(2005) ROBINS, Kevin y AKSOY, Asu. "El que busca encuentra. Mirada transnacional y conocimiento-experiencia", en Arfuch L., Pensar este tiempo. Espacios, afectos, pertenencias. Paidós, Buenos Aires.

(1985) SPIVAK, Gayatri, "Subaltern studies. Deconstructing Historiography" en Subaltern Studies IV. Wrtings on South Assian History and Society, Guha, R. ed. Delhi: Oxford University Press. Traducción de Ana Rebeca Prada y Silvia Rivera Cusicanqui. 